\title{
Memories of early childhood: Qualities of the experience of recollection
}

\author{
ROS A. CRAWLEY \\ University of Sunderland, Sunderland, England \\ and \\ MADELINE J. EACOTT \\ Durham University, Durham, England
}

\begin{abstract}
Memories judged to be recollections were contrasted with memories known to be based on secondhand sources in order to investigate the phenomenological qualities that underlie the experience of recollection. Adults rated the qualities of their recollections of an early childhood experience. Their ratings were compared with ratings of the qualities of memories of a similar autobiographical experience where the information was known to derive from other sources. Reported recollections were rated higher than memories based on other sources for many qualities, including sensory and spatial detail, location, thoughts, feelings, completeness, event detail, and pictorial representation. Comparison of the ratings of memories dating from different ages suggests that a memory may be judged to be recollected even if only a subset of the qualities characterizing recollections are present. This provides partial support for and clarification of Rubin's multiple-systems model of autobiographical memory.
\end{abstract}

Most people find it difficult to remember events that took place before about $2 \frac{1}{2}$ years of age (e.g., Eacott \& Crawley, 1998, 1999; Usher \& Neisser, 1993). Moreover, when attempting to retrieve very early memories, people frequently report that it is difficult to judge whether they really remember an event (recollection) or are reporting information gleaned from others (knowledge). The primary aim of this study was to investigate the qualities of memories that may lead to judging a memory to be a recollection, rather than merely knowledge. The secondary aim was to investigate the effect of age at the time of the experience on the phenomenology of recollection.

According to the multiple-systems model of autobiographical memory (e.g., Rubin, 1998; Rubin, Schrauf, \& Greenberg, 2003), memories arise from the products of processing in a number of component processes: an integrative memory system, imagery in individual modalities, multimodal spatial imagery, language, narrative reasoning, and emotions. Recollection is the experience of being conscious of a prior experience and is distinguishable from other mental states, including imagining and the retrieval of facts about the self. Recollection is said to depend on a metacognitive judgment based on the activation of the component processes. In support of this model, Rubin, Schrauf, and Greenberg showed that ratings of the degree to which an autobiographical memory is experienced as recollected can be predicted on the basis of

Correspondence concerning this article should be addressed to R. A Crawley, Division of Psychology, University of Sunderland, The Sir Tom Cowie Campus at St. Peter's, St. Peter's Way, Sunderland SR6 0DD, England (e-mail: roz.crawley@sunderland.ac.uk). qualities related to the component processes-particularly, visual and auditory imagery, narrative coherence, and emotion. Others have similarly emphasized the role of the qualities of a mental state in judging it to be a recollection, including its sensory-perceptual properties (Brewer, 1996; Conway \& Pleydell-Pearce, 2000; Johnson \& Raye, 1981 ) and the intensity of feeling (Hashtroudi, Johnson, \& Chrosniak, 1990; Johnson, 1988; Johnson, Foley, Suengas, \& Raye, 1988).

The principal supportive evidence for the model so far has been the demonstration that the extent of the experience of reliving the event can be predicted from qualities related to the component processes (Rubin, Schrauf, \& Greenberg, 2003). Although the evidence from Johnson and colleagues showing that the qualities of recollections differ from the qualities of imagined events is also supportive, a further test would be to examine whether the qualities of recollections differ from the qualities of memories known to be based on other sources, such as family stories.

There is some evidence to suggest that the qualities of recollections are different from the qualities of memories that are known but not recalled (Hyman, Gilstrap, Decker, \& Wilkinson, 1998; McGinnis \& Roberts, 1996), with results being generally in line with the predictions of Rubin's model. However, certain aspects of these studies make it difficult to draw firm conclusions. McGinnis and Roberts compared childhood memories with what they termed "talked about" childhood experiences. It may be that the events recalled in these two categories differed systematically in other ways that influenced memory qualities (e.g., in terms of salience or the presence of others). In Hyman et al.'s study, age at the time of the experienced event was confounded with the remembered/known distinction: The 
known events dated from a significantly younger age than did the remembered events. It is possible, therefore, that the nature of the events recalled may also have differed. In addition, there was an inherent circularity in Hyman et al.'s study that may have biased results. Participants rated childhood events that were remembered or known after having been given definitions that included memory qualities (e.g., remembering involves conscious awareness of an aspect of an event, such as the presence of visual images). It is, therefore, perhaps not surprising that the reportedly recollected memories scored higher than the reportedly known memories on conscious awareness and visual imagery.

The primary aim of the present study was, therefore, to test the prediction that differences in qualities underlie the judgment that a memory is recollected, rather than known from other sources, in a study that overcame the difficulties above. One group of adult participants recalled their experiences at the time of the birth of a younger sibling (recall group). A second group reported all that they knew about the experiences of their older sibling at the time of their own birth (knowledge group), information that could only have come from secondhand sources. In this study, the nature of the target event was constant across all groups, and the recall/knowledge distinction was clear: It was not possible for the knowledge group participants to recall the events surrounding their own birth, whereas the recall group participants might be able to remember the events surrounding their sibling's birth. Moreover, because all of the events surrounded the birth of a sibling, they could be dated with some accuracy, which also allowed us to examine any variation in the qualities of memories with differences in age at the time of the experience.

The second aim of the study was to investigate the effect of age at the time of the experience on rated qualities of memories. The most commonly cited age for the offset of childhood amnesia (e.g., Kihlstrom \& Harackiewicz, 1982; Mullen, 1994; West \& Bauer, 1999) is 3:6. (Throughout this article, ages are reported in years and monthse.g., 3:6 is 3 years and 6 months.) Accordingly, we first examined the ratings of those recalling events that took place after this cutoff, so we could be relatively confident that they would be recollections. The qualities of the memories from this group were the most important in the comparison between memories judged to be recollections and memories based on secondhand sources. In addition, we examined the ratings of those recalling events that took place when they were younger than 3:6.

The Appendix shows the qualities rated. The qualities were chosen primarily on the basis of the work of Rubin, Schrauf, and Greenberg (2003). Five categories represented Rubin's hypothesized component processes: imagery in each of the modalities (here, called sensory qualities), spatial imagery (spatial qualities), language (form of representation), narrative reasoning (narrative qualities), and emotions. In addition, on the basis of the Memory Characteristics Questionnaire (Johnson et al., 1988) and the event-rating booklet of Rubin, Burt, and Fi- field (2003), there were items asking about the completeness of and confidence in the accuracy of the information recalled, memory for thoughts, perspective, and rehearsal. Questions about rehearsal were important, since it was possible that some differences between the two groups might have been related to differences between them in the frequency with which the memories were rehearsed. An additional three items were included only for those rating their recollections: an item asking for confidence that the events were remembered, rather than known, and two items related to sense of the self in the past (Conway \& Pleydell-Pearce, 2000; Rubin, Burt, \& Fifield, 2003).

On the basis of Rubin, Schrauf, and Greenberg's (2003) account, we predicted that recollections would be rated higher than knowledge for those qualities that represented the component processes that they found to be associated with recollections: visual and auditory imagery, emotion, and narrative coherence. In addition, given the importance of visual imagery for the experience of autobiographical memories (Brewer, 1996; Brewer \& Pani, 1983; Rubin, Burt, \& Fifield, 2003), we predicted that recollections would be rated higher for pictorial than for verbal representations. By contrast, we predicted that knowledge would be rated as being more verbally than pictorially represented, because the knowledge of the events surrounding the participant's own birth is likely to have come primarily from the verbal reports of others. Equally, we predicted that recollections would be from the original field of view, whereas knowledge would be more likely to come from an outsider's field of view, because the events were not experienced firsthand.

\section{METHOD}

\section{Participants}

The participants were students from the Universities of Durham and Sunderland who responded to a request for volunteers to take part in a study of memory, for payment or course credits. The criteria for inclusion in the study were to have only one sibling whose age differed from theirs by less than 5:6 and to have no children of their own. Those who were the younger child in their family formed the knowledge group $(n=28)$. The age difference between the participants in the knowledge group and their older sibling ranged from 1:0 to 4:8. Three recall groups were formed from those who were the elder child in their family: those whose age was 3:6-5:5 $(n=$ $26)$, those whose age was 2:4-3:5 $(n=31)$, and those whose age was $\leq 2: 3$ at the time of their sibling's birth $(n=36)$. The division between the two younger groups at 2:3/2:4 was based on previous evidence from those recalling a sibling's birth, which suggested that there are some important differences in the recall of those who were younger than 2:3 at the time of the recalled events (Crawley \& Eacott, 1999; Eacott \& Crawley, 1998, 1999).

\section{Materials and Procedure}

For the purposes of another study, the participants were asked to write an account of all they could remember of the events surrounding the birth of their younger sibling (recall groups) or all they knew of the events surrounding their own birth from the point of view of their older sibling (knowledge group). Subsequently, those who were able to report something of these events rated various qualities of their memory/knowledge (see the Appendix). 
Table 1

Mean Ratings for the Older Recall, Younger Recall, and Knowledge

Groups (With Standard Deviations)

\begin{tabular}{|c|c|c|c|c|c|c|}
\hline \multirow[b]{3}{*}{ Quality } & \multirow{2}{*}{\multicolumn{2}{|c|}{$\begin{array}{c}\text { Recall } \\
2: 4-5: 5 \\
(n=19)\end{array}$}} & \multirow{2}{*}{\multicolumn{2}{|c|}{$\begin{array}{c}\text { Recall } \\
\leq 2: 3 \\
(n=55)\end{array}$}} & \multirow{2}{*}{\multicolumn{2}{|c|}{$\begin{array}{c}\text { Knowledge } \\
(n=27)\end{array}$}} \\
\hline & & & & & & \\
\hline & $M$ & $S D$ & $M$ & $S D$ & $M$ & $S D$ \\
\hline 1. Visual detail & 5.2 & 1.6 & 3.7 & 2.0 & 1.8 & 1.4 \\
\hline 2. Sound & 2.6 & 1.6 & 1.8 & 1.4 & 1.7 & 1.2 \\
\hline 3. People talking & 3.5 & 1.8 & 2.3 & 1.2 & 3.2 & 2.1 \\
\hline 4. Smell & 2.4 & 2.0 & 1.6 & 1.5 & 1.1 & 0.4 \\
\hline 5. Touch & 3.2 & 1.6 & 3.2 & 1.8 & 1.6 & 1.3 \\
\hline 6. Taste & 1.5 & 1.2 & 1.4 & 1.0 & 1.1 & 0.3 \\
\hline 11. Location & 5.6 & 1.6 & 5.2 & 1.7 & 3.8 & 2.2 \\
\hline 12. Setting familiarity & 5.4 & 1.7 & 4.5 & 2.3 & 3.8 & 2.1 \\
\hline 13. Objects (spatial arrangement) & 4.8 & 1.8 & 3.1 & 2.0 & 2.2 & 1.5 \\
\hline 14. People (spatial arrangement) & 4.5 & 2.0 & 3.5 & 1.7 & 2.3 & 1.8 \\
\hline 21. In words & 2.7 & 1.6 & 1.6 & 0.8 & 3.9 & 2.2 \\
\hline 22. In pictures & 6.0 & 1.3 & 5.2 & 1.8 & 3.4 & 2.0 \\
\hline 8. Order of events & 4.5 & 1.8 & 3.5 & 1.8 & 4.0 & 1.8 \\
\hline 9. Story line (complexity) & 3.2 & 1.6 & 2.2 & 1.2 & 2.7 & 1.4 \\
\hline 10. Story line (realism) & 5.3 & 1.5 & 4.8 & 1.4 & 5.4 & 1.3 \\
\hline 7. Event detail & 4.2 & 1.6 & 2.6 & 1.3 & 2.3 & 1.5 \\
\hline 23. Completeness of memory & 3.4 & 1.9 & 1.8 & 1.0 & 2.2 & 1.4 \\
\hline 24. How well remembered overall & 4.4 & 1.5 & 2.6 & 1.4 & 3.2 & 1.8 \\
\hline 25. Doubts about accuracy & 4.6 & 1.3 & 3.0 & 1.2 & 3.1 & 1.8 \\
\hline 17. Memory for feelings & 4.5 & 1.9 & 3.0 & 1.5 & 2.9 & 1.8 \\
\hline 15. Tone (positive/negative) & 5.4 & 1.5 & 4.6 & 1.8 & 5.5 & 1.8 \\
\hline 18. Feelings at time (positive/negative) & 5.3 & 1.7 & 4.1 & 1.9 & 4.5 & 1.9 \\
\hline 19. Feelings at time (intensity) & 4.7 & 1.3 & 4.4 & 1.6 & 3.8 & 1.6 \\
\hline 20. Memory for thoughts & 3.8 & 1.9 & 2.6 & 1.7 & 2.5 & 1.7 \\
\hline 26. Frequency: thinking of events & 4.2 & 1.6 & 3.3 & 1.3 & 3.2 & 1.7 \\
\hline 27. Frequency: talking of events & 3.6 & 1.8 & 2.8 & 1.8 & 3.3 & 1.9 \\
\hline 30. Memory certainty & 5.8 & 1.5 & 4.5 & 1.8 & & \\
\hline 28. Traveled back in time & 4.9 & 1.9 & 3.3 & 1.9 & & \\
\hline 29. Relived & 3.7 & 1.8 & 2.5 & 1.4 & & \\
\hline
\end{tabular}

Note-The numbers indicate the order of the questions (see the Appendix).

\section{RESULTS}

Twenty participants were unable to provide any information regarding the events surrounding their own or their sibling's birth, with $85 \%$ of these being from the youngest recall group $(\mathrm{Y}), 10 \%$ from the 2:4-3:5 recall group, and $5 \%$ from the knowledge group (K). Thus, the percentage of participants in each group who could report at least something of the birth events was high for all except the youngest recall group (recall $\leq 2: 3,53 \%$; recall $2: 4-3: 5$, 93\%; recall 3:6-5:5, 100\%; knowledge group, 96\%), in line with the findings of similar studies (e.g., Eacott \& Crawley, 1998). Further analysis was confined to the data provided by the participants who could remember something of the target events.

The ratings of the four groups of participants were analyzed using one-way ANOVAs. The ratings of the two older recall groups (recall 2:4-3:5 and recall 3:6-5:5) did not differ in any of the analyses (all $p$ values $>.05$ ), so these two groups were collapsed into one group $(\mathrm{O})$ for the remaining analyses reported here.

The mean ratings for each of the three groups are shown in Table 1. The ratings for items rated by all three groups were compared using one-way ANOVAs; the three items rated only by the two recall groups were compared using $t$ tests. To control for the possibility of Type I errors, the $p$ values reported for these tests are adjusted values obtained by multiplying by 30 (the number of analyses conducted), so the normally accepted alpha level of .05 is used. Given the conservative nature of the adjustment, significance levels of .06 (when rounded to two decimal places) are reported as marginally significant. For the analyses in which a significant difference emerged from the ANOVAs, multiple comparisons were conducted using Tukey tests.

\section{Sensory Qualities}

The groups differed on ratings for visual detail and for touch [visual detail, $F(2,98)=40.99, M S_{\mathrm{e}}=2.58, p<$ .0001 ; touch, $\left.F(2,98)=10.31, M S_{\mathrm{e}}=2.48, p<.01\right]$ and marginally so for smell $\left[F(2,98)=6.57, M S_{\mathrm{e}}=2.63\right.$, $p=.06]$. The ratings of both recall groups were higher than those of the knowledge group for visual detail $(p<$ .001 in both cases) and touch (O vs. $\mathrm{K}, p<.001$; $\mathrm{Y}$ vs. $\mathrm{K}, p<.01)$. Smell ratings of the older recall group were higher than those of the knowledge group $(p<.01)$. The older recall group also produced higher ratings than did 
the younger group for visual detail $(p<.01)$, but there was no difference between the two recall groups for touch or smell $(p>.05)$. There were no significant effects of group on the other sensory ratings.

\section{Spatial Qualities}

Three of the four items relating to spatial qualities showed significant differences between the groups: memory for location $\left[F(2,98)=9.32, M S_{\mathrm{e}}=3.31, p<.01\right]$, the spatial arrangement of objects $\left[F(2,98)=21.23, M S_{\mathrm{e}}=\right.$ $3.25, p<.0001]$, and the spatial arrangement of people $\left[F(2,98)=13.04, M S_{\mathrm{e}}=3.51, p<.001\right]$. Multiple comparisons showed that the older recall group gave higher ratings than did the knowledge group for these three spatial qualities ( $p<.001$ in all cases). The younger recall group also rated memory for location higher than did the knowledge group $(p<.05)$. The older recall group rated memory for the spatial arrangement of objects higher than did the younger recall group $(p<.01)$. Analysis of the ratings for setting familiarity revealed a marginally significant effect $\left[F(2,98)=6.77, M S_{\mathrm{e}}=3.74, p=.05\right]$, with higher ratings for familiarity from the older recall group than from the knowledge group $(p<.01)$.

\section{Form of Representation}

The recall groups gave higher ratings for pictorial representation than for verbal representation, whereas the ratings for the two kinds of representation were similar from the knowledge group (see Table 1). For both words and pictures, there was a significant difference between the groups [words, $F(2,98)=11.27, M S_{\mathrm{e}}=2.83, p<.01$; pictures, $\left.F(2,98)=23.21, M S_{\mathrm{e}}=2.51, p<.0001\right]$. Multiple comparisons showed that the two recall groups gave significantly higher ratings than did the knowledge group for pictorial imagery ( $\mathrm{O}$ vs. $\mathrm{K}, p<.001$; Y vs. $\mathrm{K}, p<.01$ ), and conversely, the knowledge group gave significantly higher ratings than did both recall groups for verbal representation (O vs. $\mathrm{K}, p<.01 ; \mathrm{Y}$ vs. $\mathrm{K}, p<.001)$. In addition, although the participants in the older recall group rated their memories as highly pictorial, they rated their memories as more verbal than did the younger recall group $(p<.05)$.

\section{Narrative Qualities}

The ratings for comprehensibility of the order of events and the complexity and realism of the story line showed no significant differences between the groups.

\section{Completeness}

All four items relating to the completeness of and confidence in the memory showed a difference between the groups [event detail, $F(2,98)=17.15, M S_{\mathrm{e}}=2.31, p<$ .0001 ; completeness of the memory, $F(2,98)=9.30$, $M S_{\mathrm{e}}=2.62, p<.01$; how well the events were remembered overall, $F(2,98)=10.35, M S_{\mathrm{e}}=2.50, p<.01$; and doubts about accuracy, $F(2,98)=14.85, M S_{\mathrm{e}}=1.96, p<$ .0001]. Multiple comparisons revealed the same pattern for each of the four ratings: The older recall group gave higher ratings than did the knowledge group (event detail and doubts about accuracy, $p<.001$; completeness and overall memory, $p<.01$ ) and the younger recall group (event detail, overall memory, and doubts about accuracy, $p<.001$; completeness, $p<.01$ ), but there was no difference between the ratings of the younger recall group and those of the knowledge group.

\section{Emotion}

Memory for feelings was the only one of the four items relating to emotion to show a difference between the groups $\left[F(2,98)=10.02, M S_{\mathrm{e}}=3.26, p<.01\right]$. The older recall group's ratings of memory for feelings were higher than those of both the knowledge group $(p<.01)$ and the younger recall group $(p<.01)$. The other three items (memory tone, valence of feelings at the time, and intensity of feelings at the time) gave the participants the option of responding that they did not know. Chi-square analyses of the number of participants who gave a rating and those who did not showed no difference between the groups. One-way ANOVAs using the ratings from only those participants able to provide ratings showed no difference between the groups in rated tone of the memory, positive or negative feelings, or intensity of feelings. The mean ratings for all the groups showed that remembered feelings were more positive than negative.

\section{Thought}

The difference between the groups in memory for what was thought at the time was marginally significant $\left[F(2,98)=6.59, M S_{\mathrm{e}}=3.30, p=.06\right]:$ The older recall group gave higher ratings than did the knowledge group $(p<.01)$ and the younger recall group $(p<.05)$.

\section{Perspective}

The majority of the participants reported either a viewer's or an outsider's perspective $(n=87)$, the others variously reporting using both perspectives, not visualizing the events, or using a different perspective. Chi-square analysis of the number of participants reporting a viewer's or an outsider's perspective revealed a significant difference among the three groups $\left[\chi^{2}(2)=21.74, p<.001\right]$. The knowledge group participants were more likely to take an outsider's $(n=16)$ than a viewer's perspective $(n=2)$, whereas the recall group participants, and especially the older ones, were more likely to take their own (viewer's) perspective (younger, $n=10$; older, $n=39$ ), rather than an outsider's (younger, $n=6$; older, $n=14$ ).

\section{Rehearsal}

There were no significant differences across the groups in the rated frequencies of thinking about or talking about the events since they happened.

\section{Memory Certainty}

Both recall groups had a high degree of certainty that they remembered, rather than simply knew, that the events had happened, and there was no significant difference between them. 


\section{Sense of Self in Past}

The older recall group rated their feeling of traveling back in time to be significantly higher than did the younger recall group $[t(72)=-3.32, p<.05]$, but there was no difference in the two recall groups' ratings of the degree to which the events were relived.

\section{Source of Knowledge}

All the knowledge group participants reported that members of their family other than their sibling were a source of knowledge. In addition, $11(41 \%)$ reported that their sibling specifically had provided information, and 11 that photos were an additional source. None reported video as a source of information.

\section{DISCUSSION}

A comparison of the qualities of memories judged to be recollections with those of memories based on secondhand sources revealed differences in almost all the qualities examined. As compared with those participants who rated what they knew from other sources, those who rated what they judged to be their firsthand recollections (from the age of 2:4-5:5) reported more sensory detail in terms of visual, smell, and touch memory; better memory for spatial qualities, feelings, and thoughts; and higher ratings for completeness of and confidence in the accuracy of the memory. In addition, they reported that their memories came in a more pictorial and less verbal form and that they came from the viewer's perspective (their own), rather than from that of an outsider. These findings are largely consistent with the predictions based on Rubin's multiple-systems model, in a study that avoids the problems with the previous studies identified in the introduction. Thus, the results provide the first good evidence for a distinction between memories that are judged to be based on firsthand recollections and memories known to be based on secondhand sources in terms of sensory and spatial qualities, memory for emotion and thought, completeness and event detail, perspective, and verbal/pictorial representation.

There are some interesting dissociations in the findings. For example, although high ratings for some sensory modalities characterized recollections (visual and spatial detail, touch, and smell), others did not differ between recollection and knowledge (taste and sound). This provides support for the importance of sensory imagery for recollection advocated by many (e.g., Conway \& PleydellPearce, 2000; Johnson \& Raye, 1981; Rubin, Schrauf, \& Greenberg, 2003) but suggests that recollections may favor some sensory qualities. However, it should be noted that ratings for taste and sound yielded low ratings across all groups, perhaps indicating a floor effect. Nonetheless, the ratings of the older recall group for visual detail and spatial qualities were particularly high, a finding that supports the view that visual imagery is the most important of all sensory imagery in recollection (e.g., Brewer \& Pani,
1983; Rubin, Burt, \& Fifield, 2003) and that it is important in separating autobiographical recollections from known facts about one's life (Brewer, 1996).

In agreement with the predictions from Rubin's model, emotion also distinguished recollections and knowledge. This difference was not in terms of emotional valence and intensity, but in terms of the detailed knowledge available about feelings. In addition, those judging their memories to be recollections reported better memory for their thoughts at the time. Although similar findings have been reported (Hyman et al., 1998; McGinnis \& Roberts, 1996), our study demonstrates the differences without the potential confound with the type of event being recalled.

Memories judged to be recollections did not differ from those based on knowledge in terms of their narrative properties. In this respect, our results differ from those of Rubin, Schrauf, and Greenberg (2003), who found that ratings of a memory as a coherent story predicted ratings of recollection. One might speculate that the two types of memories derive narrative properties for different reasons: the knowledge-based memories from the initial act of recounting, and the recollected memories through acts of reminiscence and sharing of memories. Nevertheless, our results show that both recollections and known facts can have narrative properties.

The commonly cited age for the offset of childhood amnesia is around 3:6 (e.g., Kihlstrom \& Harackiewicz, 1982; Mullen, 1994; West \& Bauer, 1999). Nonetheless, our study indicates that memories from before the age of 3:6 are quite common (see also Eacott \& Crawley, 1998; Usher \& Neisser, 1993) and also that memories recalled from the ages of 2:4-3:5 do not differ qualitatively from those recalled from the ages of 3:6-5:5. Moreover, the results also show that it is not uncommon for those who were even younger $(\leq 2: 3)$ to believe that they recollected something of their experience. In line with our previous findings (Eacott \& Crawley, 1998, 1999), around half of the participants whose age was under 2:4 when their sibling was born were able to report something of the events surrounding the birth.

It is possible, of course, that the very early memories reported by the youngest recall group are not true recollections and that they derive, instead, from a different source (e.g., family stories). Although we can be sure that the reported memories of the knowledge group are not recollections (because they are reporting events surrounding their own birth), we cannot be so confident about the source of the memories reported to be recalled by the youngest recall group or, indeed, any of the recall groups. There is no external criterion by which to judge the validity of the reported memories as "true" recollections. However, we do know that these are mental states that the participants judge to be recollected memories and that even those in the youngest recall group are quite confident that these memories are remembered, rather than known (see Table 1). Thus, the ratings indicate the qualities of memories that are judged to be recollections, and it is informative to consider the 
ways in which the ratings of the youngest recall group are similar to and differ from those of the older recall group.

The ratings show that many of the memory qualities reported by the youngest recall group are similar to those reported by the older recall group and dissimilar to those reported by the knowledge group (visual detail, touch, location, perspective, and pictorial/verbal representation). Thus, in some important respects, the younger recall group reported memories with qualities similar to those reported by the older group, whose age at the time of their experience allows us to be reasonably confident that they may well be able to recollect. It might be tempting to conclude that because of these similarities, the younger recall group can also recollect. However, it is not possible to do so. If an important determinant of the judgment about whether a particular mental state represents a recollection is the qualitative character of that mental state, it should not be surprising to find qualitative similarities between the reported recollections of the two recall groups. What our results suggest is that the qualities of visual detail, touch, location, and form of representation are important in the judgment of which mental states are recollections. Thus, memories that are judged by both recall groups to be recollections differ from those that we know cannot be recollections (and are not experienced as recollections): They contain more visual detail, more details of touch, and more information regarding location and are more likely to come to mind in pictures, rather than in words.

Even more interesting, perhaps, are the ways in which the qualities of the memories of the youngest recall group differed from those of the older recall group. The younger group gave significantly lower ratings for completeness of and confidence in the accuracy of the memory, details of feelings and thoughts, and the feeling of traveling back in time. Nonetheless, the younger group still made the judgment that what they recalled were memories based on recollection. Indeed, there was no difference between the two recall groups in their confidence that these were recollected, rather than known, memories. This suggests that it is not necessary to retrieve a memory that is highly complete or that has a lot of information about feelings and thoughts for it to be judged to be a recollected memory. And although these results do not rule out the importance of the sense of the self in the past for this judgment, particularly because the two recall groups did not differ in their ratings for reliving the experience, they leave open the question of how important it is for judging that very early memories are recollected. Counter to the predictions of Conway and Pleydell-Pearce (2000), recollection was not associated with a high rating for the feeling of reliving the events or traveling back in time. Our results suggest that only some of the qualities that distinguish recollections from knowledge-based memories need to be present for a recollection judgment to be made. It may be that there is a threshold number of recollection qualities that need to be present or that there are some qualities that are more important than others. To investigate this further, studies based on a wider variety of recall events are needed.
In conclusion, adults' early recollections of a sibling's birth differ from memories for a similar autobiographical event known to be based on secondhand sources in terms of a number of phenomenological qualities, including richness of sensory characteristics relating to visual detail, smell, and touch, information related to location and the spatial arrangements of objects and people, and information about feelings and thoughts at the time of the event. In addition, they are more complete, contain more event details, and are more likely to come to mind in pictorial, rather than verbal, form and from the viewer's, rather than from an outsider's, perspective. These differences are in line with predictions from Rubin, Schrauf, and Greenberg's (2003) model and strengthen support for that model. The similarities and differences between the qualities of memories of those who were 2:3 or younger and those who were between 2:4 and 5:5 at the time of their sibling's birth further suggest that a memory may be judged to be recollected even if only a subset of the qualities characterizing recollections are present.

\section{REFERENCES}

BREWER, W. F. (1996). What is recollective memory? In D. C. Rubin (Ed.), Remembering our past: Studies in autobiographical memory (pp. 19-66). Cambridge: Cambridge University Press.

Brewer, W. F., \& Pani, J. R. (1983). The structure of human memory. In G. H. Bower (Ed.), The psychology of learning and motivation (Vol. 17, pp. 1-38). New York: Academic Press.

Conway, M. A., \& Pleydell-Pearce, C. W. (2000). The construction of autobiographical memories in the self-memory system. Psychological Review, 107, 261-288.

CraWley, R. A., \& EACOTT, M. J. (1999). Memory for early life events: Consistency of retrieval of memories over a one-year interval. Memory, 7, 439-460.

Eacott, M. J., \& Crawley, R. A. (1998). The offset of childhood amnesia: Memory for events that occurred before age 3. Journal of Experimental Psychology: General, 127, 22-33.

Eacott, M. J., \& Crawley, R. A. (1999). Childhood amnesia: On answering questions about very early life events. Memory, 7, 279-292.

Hashtroudi, S., Johnson, M. K., \& ChrosniaK, L. D. (1990). Aging and qualitative characteristics of memories for perceived and imagined complex events. Psychology \& Aging, 5, 119-126.

Hyman, I. E., Jr., Gilstrap, L. L., Decker, K., \& Wilkinson, C. (1998). Manipulating remember and know judgements of autobiographical memories: An investigation of false memory creation. Applied Cognitive Psychology, 12, 371-386.

Johnson, M. K. (1988). Reality monitoring: An experimental phenomenological approach. Journal of Experimental Psychology: General, 117, 390-394.

Johnson, M. K., Foley, M. A., Suengas, A. G., \& Raye, C. L. (1988). Phenomenal characteristics of memories for perceived and imagined autobiographical events. Journal of Experimental Psychology: General, 117, 371-376.

Johnson, M. K., \& RaYe, C. L. (1981). Reality monitoring. Psychological Review, 88, 67-85.

Kinlstrom, J. F., \& Harackiewicz, J. M. (1982). The earliest recollection: A new survey. Journal of Personality, 50, 134-148.

McGinnis, D., \& Roberts, P. (1996). Qualitative characteristics of vivid memories attributed to real and imagined experiences. American Journal of Psychology, 109, 59-77.

Mullen, M. K. (1994). Earliest recollections of childhood: A demographic analysis. Cognition, 52, 55-79.

RuBIN, D. C. (1998). Beginnings of a theory of autobiographical remembering. In C. P. Thompson, D. J. Herrmann, D. Bruce, J. D. Read, D. G. Payne, \& M. P. Toglia (Eds.), Autobiographical memory: Theoretical and applied perspectives (pp. 47-67). Mahwah, NJ: Erlbaum. 
Rubin, D. C., Burt, C. D. B., \& Fifield, S. J. (2003). Experimental manipulations of the phenomenology of memory. Memory \& Cognition, 31, 877-886.

Rubin, D. C., Schrauf, R. W., \& Greenberg, D. L. (2003). Belief and recollection of autobiographical memories. Memory \& Cognition, 31, 887-901.
Usher, J. A., \& Neisser, U. (1993). Childhood amnesia and the beginnings of memory for four early life events. Journal of Experimental Psychology: General, 122, 155-165.

West, T. A., \& Bauer, P. J. (1999). Assumptions of infantile amnesia: Are there differences between early and later memories? Memory, 7, 257-278.

\section{APPENDIX
Quality Rating Questions for Recall Participants}

Sensory Qualities

1. My memory for these events involves visual detail: $1=$ little or none; $7=$ a lot

2. My memory for these events involves sound: $1=$ little or none; $7=$ a lot

3. As I remember these events, I or other people are talking: $1=$ not at all; $7=$ very clearly

4. My memory for these events involves smell: $1=$ little or none; $7=$ a lot

5. My memory for these events involves touch: $1=$ little or none; $7=$ a lot

6. My memory for these events involves taste: $1=$ little or none; $7=$ a lot

\section{Spatial Qualities}

11. My memory for the location where the events took place is: $1=$ vague; $7=$ clear/distinct

12. The general setting is: $1=$ unfamiliar; $7=$ familiar

13. The relative spatial arrangement of objects is: $1=$ vague $; 7=$ clear/distinct

14. The relative spatial arrangement of people is: $1=$ vague; $7=$ clear/distinct

\section{Form of Representation}

21. As I remember these events, they come to me in words: $1=$ not at all; $7=$ definitely

22. As I remember these events, they come to me in pictures: $1=$ not at all; $7=$ definitely

\section{Narrative Qualities}

8. The order of events is: $1=$ confusing; $7=$ comprehensible

9. The story line is: $1=$ simple $; 7=$ complex

10. The story line is: $1=$ bizarre; $7=$ realistic

\section{Completeness}

7. My memory for these events is: $1=$ sketchy; $7=$ very detailed

23. My memory for these events is: $1=$ fragmentary; $7=$ complete

24. Overall, I remember these events: 1 = hardly; 7 = very well

25. Do you have any doubts about the accuracy of your memory for these events? $1=$ a great deal; $7=$ none whatsoever

\section{Emotion}

17. I remember how I felt at the time when the events took place: $1=$ not at all; $7=$ definitely

15. The overall tone of the memory is: $1=$ negative; $7=$ positive; or don't know

18. My feelings at the time were: $1=$ negative; 7 = positive; or don't know

19. My feelings at the time were: $1=$ not intense; 7 = intense; or don't know

\section{Thought}

20. I remember what I thought at the time: $1=$ not at all; $7=$ very clearly

\section{Perspective}

16. From what perspective are the events visualized? 1 = your own field of view i.e., as you originally viewed them; 2 = an outside observer's field of view i.e., as someone else might have viewed them with you present in the scene; 3 = neither perspective fits; $4=$ the events are not visualized

\section{Rehearsal}

26. Since these events happened, I have thought about the events: $1=$ not at all; 7 = many times

27. Since these events happened, I have talked about the events: $1=$ not at all; $7=$ many times

\section{Memory Certainty}

*30. As I think about the events I have recalled, I am sure I can actually remember them rather than just knowing that they happened: $1=$ not at all sure; 7 = very sure 


\section{APPENDIX (Continued)}

\section{Sense of Self in Past}

*28. As I remember these events, I feel that I travel back to the time when they happened, and that I am a participant in those events again rather than an outside observer tied to the present: $1=$ not at all; $7=$ very much so

*29. As I remember these events, I feel as though I am reliving the original events: $1=$ not at all; $7=$ very clearly

Source of Knowledge

**31. My knowledge of these events is based on the following sources (tick one or more, as appropriate): my elder brother/sister, other members of my family, photographs, videos, other (please specify).

Note-The numbers indicate the order of the questions. For knowledge group participants, the wording was changed where appropriate to refer to knowledge (not memory) and the participant's sibling's point of view (rather than that of the participant). * Recall groups only. ${ }^{* *}$ Knowledge group only.

(Manuscript received June 26, 2003;

revision accepted for publication March 19, 2005.) 